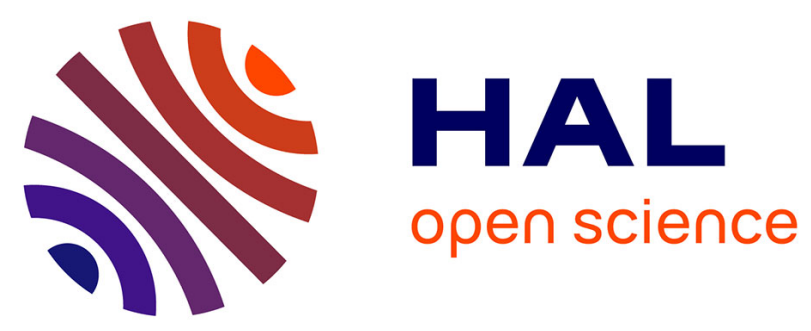

\title{
Trade-wind waves and mud dynamics on the French Guiana coast, South America: input from ERA-40 wave data and field investigations
}

\author{
Nicolas Gratiot, Antoine Gardel, Edward J. Anthony
}

\section{To cite this version:}

Nicolas Gratiot, Antoine Gardel, Edward J. Anthony. Trade-wind waves and mud dynamics on the French Guiana coast, South America: input from ERA-40 wave data and field investigations. Marine Geology, 2007, 236, pp.15-26. 10.1016/j.margeo.2006.09.013 . hal-00101721

\section{HAL Id: hal-00101721 \\ https://hal.science/hal-00101721}

Submitted on 28 Sep 2006

HAL is a multi-disciplinary open access archive for the deposit and dissemination of scientific research documents, whether they are published or not. The documents may come from teaching and research institutions in France or abroad, or from public or private research centers.
L'archive ouverte pluridisciplinaire $\mathbf{H A L}$, est destinée au dépôt et à la diffusion de documents scientifiques de niveau recherche, publiés ou non, émanant des établissements d'enseignement et de recherche français ou étrangers, des laboratoires publics ou privés. 


\title{
Trade-wind waves and mud dynamics on the French Guiana coast, South America: input from ERA-40 wave data and field investigations
}

\author{
Nicolas Gratiot ${ }^{\mathrm{a} 1}$, Anto ine Gardel ${ }^{\mathrm{b}}$, Edward, J. Anthony ${ }^{\mathrm{b}}$
}

a'Laboratoire d'Ecologie Littorale, (UR053 Elisa) IRD Guyane, BP 165, Rte de Montabo, 97323 Cayenne, French Guiana

${ }^{\mathrm{b}}$ Coastal Geomorphology and Shoreline Management Unit (GéoDAL), EA 3599, Université du Littoral Côte d'Opale, MREI 2, 189a Avenue Maurice Schumann, 59140 Dunkerque, France

${ }^{1}$ Present address: LTHE (UMR IRD-CNRS-UJF-INPG) 1025, rue de la piscine, BP 53, 38041 Grenoble cedex 9, France.

\begin{abstract}
The South American coast between Brazil and Venezuela is affected by longshore migrating mud banks derived from the fine-grained Amazon sediment discharge. Onshore mud migration prevails over shallow 'bank' areas alternating alongshore with deeper 'inter-bank' areas. The transport on the inner shelf, and attachment to the shoreline, of this migrating mud has been attributed mainly to wind waves. However, the lack of in situ data on waves hampers understanding of the relationship between waves and mud dynamics. A 44-yr record (1960-2004) of the ERA-40 wave dataset generated by the European Centre for Medium-Range Weather Forecasts (ECMWF) was used, in conjunction with field investigations in French Guiana, to define both event-scale and longer-term patterns of mud mobilisation induced by waves. The ratio $H_{0}^{3} / T^{2}$, combining wave height $H$ and period $T$, and the angle of wave incidence $\alpha$, were singled out as the most relevant parameters for describing wave forcing. Typical 'bank' and 'inter-bank' profiles and correspond ing mud densities, and a 3-month record of changes in the thickness of the fluid mud layer in an estuarine navigation channel were monitored by echo-sounding from October 2002 to January 2003. An 80day record of bed-level changes in the intertidal zone was obtained from August to November 2004 using a press ure transducer. The results on the wave regime of French Guiana confirm a distinctly seasonal pattern, and highlight an increase in $H_{0}^{3} / T^{2}$ over the 44-yr period related to an increase in Trade wind velocities determined from corresponding trends in Atlantic wind pseudo-stress off the South American coast. Wave
\end{abstract}


forcing over bank areas leads to the liquefaction of a 1-3 m-thick layer of mud that is transported onshore (and alongshore by the longshore component of wave energy). The ep is odic nature of high wave energy events generally results in the formation of mud bar features from the shoreward mobilisation of gel-like fluid mud. The effect of waves on mud is particularly marked following long periods of low energy, and especially at the ons et of the high wave energy season (Oc tober to May), when even moderate wave energy events can lead to significant mobilis ation of mud.

Significant phases of increased wave energy are attended by higher long-term (annual) rates of longshore mud bank migration but the correlation is rather poor between the wave forcing parameter $H_{0}{ }^{3} / T^{2}$ and migration rates because stronger wave forcing is generally associated with low angles of wave incidence. This suggests a complementary role of other hydrodynamic mechanisms, such as geostrophic and tidal currents, in longshore mud bank migration.

Keywords: Trade-wind waves, ER A-40 wave dataset, mud banks, mangroves, French Guiana.

\section{Introduction}

The $1600 \mathrm{~km}$-long coast between the mouths of the Amazon and the Orinoco Rivers (Fig. 1) is bounded by the longest stretch of muddy shoreline in the world. These muddy deposits have been supplied by the Amazon and transported northwestwards towards the Orinoco Delta (Augustinus, 1978; Eisma et al., 1991). Mud occurs in various stages of concentration and consolidation ranging from very high suspended sediment concentrations ([1-10] $\left.\mathrm{g}^{-1}\right)$, through fluid mud ([10-300] $\left.\mathrm{g}^{-1}\right)$, to settled mud which, in turn ranges from under-consolidated $\left(\leq 650 \mathrm{~g} \mathrm{l}^{-1}\right)$ to consolidated beds $\left(\geq 750 \mathrm{~g} \mathrm{l}^{-1}\right)$. Consolidated mud forms the inner shelf $(0$ to $-20 \mathrm{~m})$ relict bed surface (Bouysse et al., 1977; Pujos et al., 1990) over which mud banks comprising fluid and under-consolidated mud migrate in shallow inshore water depths of 5 to $20 \mathrm{~m}$ (Allison et al., 2000). The basal shelf relict deposits range in age from over 40 ky to Holocene (Cleac'h, 1999). 
Froidefond et al. (1988) and Gardel and Gratiot (2005) have shown that over the last 25 years, the French Guiana coast between Cayenne and Kourou (Fig. 1) experienced the passage of two major mud banks separated by an active inter-bank period, from the middle 1980 s to the early 1990s (Fig. 2a). Mud banks exhibit low multi-annually averaged migration rates $\left(0.2-1.8 \mathrm{~km} \mathrm{y}^{-1}\right)$ in the early $1980 \mathrm{~s}$ and high rates $\left(1.8-3.0 \mathrm{~km} \mathrm{y}^{-}\right.$ $\left.{ }^{1}\right)$ over the last 15 years. Overall, the migration rates calculated by Gardel and Gratiot (2005) are higher than those calculated by Froidefond et al. (1988). This is not surprising, as the short term approach adopted by the latter workers, and based on aerial photographic interpretation, coincided with a period of especially low forcing, as will be demonstrated hereafter. Maximum mangrove retreat was observed in the late 1980s, at the height of the inter-bank period. As shown on Fig. 2b, the annual retreat of the mangrove front over the $60 \mathrm{~km}$ shoreline attained up to $100 \mathrm{~m}$ between 1986 and $1991 \mathrm{in}$ inter-bank areas, and slightly less $\left(\approx 80 \mathrm{~m} \mathrm{y}^{-1}\right)$ in areas fronted by mud banks. During the rapid bank migration period (1995-2002), the coastline experienced both mangrove colonisation and retreat. This indicates a complex dynamic system that will be further discussed later.

A number of recent studies have focused on the spatial and temporal dimensions of mud bank migration and interaction with the shoreline, using geochemical signatures (Allison and Lee, 2004), aerial photographic and satellite image data (Fromard et al., 2004; Lefebvre et al., 2004), and maps and Holocene data (Plaziat and Augustinus, 2004). This collection of studies complements attempts, in the last three decades, aimed at characterizing the hydrodynamic forcing governing mud bank migration. This migration has been attributed by Allison et al. (1995) to currents generated by trade winds, with tidal currents and waves playing a determining role in maintaining sediment suspension in the coastal zone. Various experimental efforts on mud transport by waves, and field investigations, have, however, suggested a leading role for wind-generated waves in mud 
bank migration (Augustinus, 1978, 2004; Wells and Coleman, 1978; Eisma et al., 1991; Lakhan and Pepper, 1997). Wave-mud interaction involves: (1) mud liquefaction by waves as they are dissipated in the highly viscous muddy layer, (2) mud bank migration generated by the longshore component of waves obliquely incident to the shore. Apart from variations in sediment supply from the Amazon, changes in the intensity and direction of the trade winds and their effects on waves have also been held responsible for temporal variability in mud bank migration rates (Eisma et al., 1991; Allison et al., 1995, 2000). However, a finer resolution of the role of waves in driving mud transport is hampered by the dearth of wave statistics for this coast. It is generally admitted from offshore and coastal observations, and from remote sensing data, that the waves on the French Guiana coast arrive from an east to northeast direction in response to the prevailing trade winds. Typical periods of 6 to $10 \mathrm{sec}$, and offshore heights of up to $1.5 \mathrm{~m}$ have been reported (NEDECO, 1968; Anthony et al., 2002; Anthony and Dolique, 2004).

The lack of long-term records of waves on the Guiana coasts has been mediated by recourse to proxy data on wave-generating winds by Eisma et al.(1991). Their approach consisted in using the angle of shore incidence of synoptic winds, measured at a height of $500 \mathrm{~m}$ in Kourou (Fig. 1), as a surrogate for assessing temporal variations in the intensity of longshore drift, and hence mud bank migration rates. This approach was further used by Augustinus (2004) to explain both changes in rates of mud bank migration and in the lengthening of mud banks. While this crude approach yields useful information at a broad level, in the absence of wave data, it remains rather semi-empirical and does not provide a clear understanding of the physical relationship between the main forces (waves, currents, tides) and their effects (sediment transport, mudflat formation ...). Hence a need for more studies based on direct wave data coupled with in situ monitoring of mud mobilisation. 
In this paper, wave data acquired from the European Centre for Medium-Range Weather Forecasts (ECMWF) are used, in conjunction with surveys on mud concentrations in the coastal zone, to further contribute to the understanding of the role of waves in patterns of mud mobilisation at different temporal and spatial scales.

\section{Data acquisition}

The wave parameters (significant wave height and mean wave period) used in this study are hindcast data of swell off the coast of French Guiana between 1960 and 2004, generated by the ECMWF WAM wave model. The wave data for the French Guiana coast are part of the ERA-40 dataset, which involves a reanalysis of global meteorological variables (Sterl and Caires, 2005). The ERA-40 reanalysis is the first in which an ocean wind-wave model is coupled to the atmosphere, and the quality of the wave data has been extensively validated against buoy and altimeter data. Sterl and Caires (2005) and Caires and Sterl (2005) demonstrated a very good correlation between the ERA-40 data and these sources, except for high waves (significant wave height, $H_{s}>5 \mathrm{~m}$ ) and low waves $\left(H_{s}<1 \mathrm{~m}\right)$ which tend, respectively, to be under- and over-estimated. As will be seen later, these critical wave conditions are never met along the French Guiana coast. Considering the lack of in situ data on waves for this coast, the ERA-40 wave input, generated for the area just offshore of French Guiana (geographical coordinates $5^{\circ} \mathrm{N}$ and $52^{\circ} \mathrm{W}$, Fig. 1), constitutes a useful basis for examining mud bank migration, given the leading role of waves in such migration. The deep-water wave data are correlated with bank migration rates and with shorter-term mud mobilisation events. In the WAM model, the wave spectrum is computed by integration of the energy balance equation without 
prior restriction of the spectral shape. The interested reader is referred to Komen et al. (1994), Sterl and Caires (2005) and Caires and Sterl (2005) for details on the WAM model and on derivation and testing of the main wave climate parameters, and to Woods (2005) for an overview of the European approach to medium-range forecasting. The three parameters used in this study are significant deepwater wave height $H_{s}$, wave period $T$, and wave approach angle $\alpha$. The physical modifications of waves (notably $H_{s}$ and $\alpha$ ) induced by dissipation and refraction in shallow water, are beyond the scope of the paper, which insists on the relationship between temporal deep-water wave parameter trends and mud mobilisation.

In order to compare the wave data with mud mobility patterns, data on mud concentrations and on bank surface morphology were obtained from three sites (Fig. 1) covering both the inshore and nearshore zones, using two different techniques. The Kaw site is situated in an area of pristine muddy and mangrove-colonised coast with no human presence, while both the Kourou and Cayenne sites are located in urbanised areas of coast, the former subject to constant dredging of mud in order to maintain a navigable access to the port of Kourou. Two nearshore profiles, respectively from an inter-bank and a mud bank area $20 \mathrm{~km}$ apart, off Kaw (Fig. 1), were obtained by echo-sound ing in November 2002 at a frequency of $210 \mathrm{Khz}$. The surveys were carried out at high tide water, as this gives the maximum echo-sounding coverage, and the profiles tied to the Lowest Astronomical Tide datum. The echo-sounding technique is based on the fact that the main reflection occurs on the major density stratification. Echo-sounding gives the position of the top of a fluid mud layer, if it exists, or the position of the consolidated bed otherwise. Lead-line measurements give the position of an iso-density that is considered to be the consolidated bed. Ideally, the two techniques should be used simultaneously in muddy environments in order to measure both the top of the fluid mud layer and the 
consolidated bed. This was the case in the navigation channel of Kourou (Fig. 1), but was not always possible in the inter-bank and mud bank areas of Kaw. In these areas, the echo-sounder was used in coastal waters down to depths of two metres. For shallower water depths (between 0 and $2 \mathrm{~m}$ ), where navigation problems preclude the use of an echo-sounder, a lead line was used. Despite these limitations, the use of the two methods provides consistent data in this muddy environment, a point specifically discussed and developed in Gratiot et al. (2003). The GPS horizontal positioning accuracy for the echosounder profiles is about $\pm 10 \mathrm{~m}$ and the echo-sounder and lead-line measurement accuracies respectively about $\pm 0.5 \mathrm{~m}$ and $\pm 0.1 \mathrm{~m}$. Some bed sediment sampling was carried out during the monitoring of the profiles in order to examine sediment density along the water depth profiles (Fig. 1). These density values have a precision range of about $\pm 5 \%$.

Data on variations in the thickness of the fluid mud layer were obtained in the channel of Kourou harbour (Fig. 1) from October 2002 to January 2003. This harbour is on the west bank of the Kourou River estuary and is essentially used by the European Space Agency (ESA) to service the satellite launching pad of Kourou. The harbour is periodically affected by the arrival of patches of fluid mud that hinder navigation, and that require dredging to maintain an appropriate depth above the estuarine channel. The echo-sounder was set at a frequency of $210 \mathrm{Khz}$ to detect the top of the fluid mud layer. The depth of this layer above the consolidated mud bed was then measured by lead-line soundings.

To measure periodic wave-induced fluid mud loading onshore which induces bedlevel changes, a pressure sensor was deployed in the intertidal zone in front of the IRD research station at Anse du Chaton, Cayenne (Fig. 1), $500 \mathrm{~m}$ from the shore, for 80 days (19 August to 7 November 2004). This deployment was based on the principle, from on- 
going experimental work aimed at high-resolution monitoring of bank surface morphology, that this zone is periodically affected by gel-like mobile patches of fluid mud. Instantaneous measurements were carried out by the sensor once every 5 minutes over the 80-day survey. Once the tidal signal is removed from the transducer signal, the system provides changes in water surface and mud surface elevations due to highfrequency loading by waves, and changes in mud surface elevation due to loading by mud.

\section{Results}

Wave data

The mean deepwater wave height data show a bimodal distribution characterized by a high-energy season with high significant wave values $\left(H_{s}\right)$ from about October to May, and a low-energy season from about June to September (Fig. 3a). This seasonal signal matches that of the generating trade wind waves, as do the wave periods $(T)$ in the range of $7-10 \mathrm{~s}$ (Fig. $3 \mathrm{~b}$ ). $H_{s}$ values range mainly from 1 to $2.5 \mathrm{~m}$, and correspond to those published in the literature from brief wave recorder deployments off Surinam (Wells and Coleman, 1978; Wells 1983) and French Guiana (Anthony and Dolique, 2004).

To assess the effect of waves on mud bank migration rate, the parameterization proposed by Rodriguez and Mehta (1998) was used. It is clear that wave refraction and diffraction play a significant role by concentrating energy at specific places, and by creating energy gradients alongshore. Along the Kerala coast in India, for instance, wave refraction due to offshore bathymetry leads to shore-fast mud bank formation at known locations of wave en ergy concentration (Mathew and Baba, 1995). Along the leading and trailing edges of the mud banks of the South American coast, the rheological 
characteristics of mud can vary widely alongshore, as reported by Allison and Lee (2004). This undoubtedly induces important refraction and diffraction effects, but on the main body of the mud bank (essentially the subtidal part), the gradients in mud characteristics are basically cross-shore, and result from the dissipation of wave energy by viscous effects during wave propagation. In this main part of the mud bank, slopes are usually very small so that refraction of waves is undoubtedly less important than wave damping. From these considerations, the analytical approach proposed by Rodriguez and Mehta (1998), and postulating fluid mud streaming induced by wave damping as the major forcing factor in the migration of mud bank, appears to be the most suitable. Their analytical model, based on a physical statement of the problem, characterizes fluid mud streaming under non-breaking wave shear stress and is expressed by:

$$
\begin{aligned}
& C_{\text {bank }}=\frac{1}{3} \sin \alpha \cdot\left(\frac{\rho_{w} H_{0}^{3}}{\mu_{m} T_{2}}\right)\left\{\frac{h_{m}^{*} \rho_{m}^{*}\left(2-\rho_{m}^{*}\right)}{h_{w}^{*}\left(\rho_{m}^{*}-1\right)} \overline{\eta_{m}^{*} \frac{\partial \eta_{w}^{*}}{\partial_{s}^{*}}}-\frac{h_{m}^{*} \rho_{m}^{*}\left(2-\rho_{m}^{*}\right)+h_{w}^{*}\left(\rho_{m}^{*}-1\right)+\rho_{m}^{*} h_{w}^{*} h_{m}^{*}}{h_{w}^{*}\left(\rho_{m}^{*}-1\right)}\right. \\
& \times \overline{\eta_{m}^{*} \frac{\partial \eta_{w}^{*}}{\partial s^{*}}}\left[\left(h_{m}^{*}+h_{w}^{*} b_{m}^{*}-h_{w}^{*}\right] \overline{\eta_{m}^{*} \frac{\partial \eta_{w}^{*}}{\partial s^{*}}}\right\}
\end{aligned}
$$

where $C_{\text {bank }}$ is mud bank celerity, $\alpha$ is the angle between the direction of wave propagation and the shoreline, $\rho_{w}$ is sea water density, $\mu_{m}$ a representative mean viscosity, and $H_{0}$ a characteristic offshore wave height associated with a characteristic period $T$. Quantities superscripted by an asterisk are dimensionless values. $h^{*}, \rho^{*}, \eta^{*}$ refer to layer thickness, density, and interfacial set-up, respectively. Quantities subscripted by $m$ and $w$ refer to mud and water, respectively. $s$ denotes distance in the direction of wave propagation.

Equation (1) implies that fluid mud streaming due to waves is the major agent responsible for mud bank migration. This aspect will be discussed later. The right hand side of the equation comprises two functional parts. The bracket terms denote the external input of energy by wave forcing relative to the mean rheological state of the mud bank, 
and the embrace terms refer to the normalized interaction of incident waves with the water-fluid mud column. As the purpose of the paper is to examine the overall impact of gravity waves on mud bank migration rates, the angle of wave incidence $\alpha$ and the ratio $H_{0}{ }^{3} / T^{2}$ constitute the most relevant parameters for describing wave forcing.

Figure 4 shows the time series of the wave parameters over the period 1960 to 2004. In order to highlight year-to-year variability, the mean of the $10 \%$ and $30 \%$ highest values are also shown (circles and dots, respectively). The years 1992 and 1993 were discarded because they correspond to a period of assimilation of faulty ERA fast delivery product wave height data (Sterl and Caires, 2005). Since 1996, there has been a net increase of the overall wave forcing ratio (Fig. 4c). This increase is mainly due to an increase of the highest values (circles in Fig. 4c) and is smoothed when considering all data (crosses in Fig. 4c). The wave height increase over the entire dataset attains nearly $1.3 \mathrm{~cm} \mathrm{y}^{-1}$, and nearly $2.0 \mathrm{~cm} \mathrm{y}^{-1}$ for the $10 \%$ highest values.

This increasing wave forcing trend closely matches a trend observed in tropical Atlantic wind patterns. The wind evolution trends have been determined from pseudostress data available on the URL page www.coaps.fsu.edu/woce/SAC/atlantic. Derivation and post-treatment of data from the URL source are reported in the appendix. Focus here is on the analysis of variability in forcing. The pluri-decennial wind trend shows an increase in the annually averaged speed $\left(+2.3 \mathrm{~cm} \mathrm{~s}^{-1} \mathrm{y}^{-1}\right.$, Fig. 5). This trend closely corresponds to that deduced from the synoptic wind field in Kourou (Eisma et al., 1991; Augustinus, 2004). It is much more pronounced for the strong wind season (JanuaryMay), which is characterized by a general increase of $2.9 \mathrm{~cm} \mathrm{~s}^{-1} \mathrm{y}^{-1}$. The strong wind season also shows fluctuations that include two multi-annual weak periods from 1964 to 1970 and from 1978 to 1984 . 
Averaged over a year, the angle of wave incidence, $\alpha$, the importance of which has been emphasised in mud bank migration (Eisma et al., 1991; Lakhan and Pepper, 1997), always exhibits a relatively constant positive value of about $10-15^{\circ}$ (Fig. $4 \mathrm{~d}$, crosses). The pattern is radically different when the $10 \%$ highest values are considered. There are several years exhibiting nil angles or even negative values, indicating a potential longshore wave energy gradient towards the southeast, especially since 1995. It is worth noting in passing that the data do not highlight the $15-20 \mathrm{yr}$ cycle of fluctuations in wind incidence angle proposed by Eisma et al. (1991) as the major agent in mud bank generation.

\section{Mud data and their relationship to wave patterns}

The nearshore profiles of the typical inter-bank and mud bank areas in the Kaw area are presented in Fig. 6. The inter-bank profile (Fig. 6a) exhibits an almost 1/1000 linear to slightly convex slope from $-15 \mathrm{~m}$ to $0 \mathrm{~m}$, and a concave profile above. The corresponding bed sediment (Fig. 6c) has a mud density of about $1450 \mathrm{~kg} \mathrm{~m}^{-3}$ over the whole profile. The mud bank profile (Fig. 6b) is rather different. It shows a more convex slope and is characterized by a mean bottom layer density of about $1350 \mathrm{~kg} \mathrm{~m}^{-3}$. At 6 to $7 \mathrm{~km}$ offshore, the mud bank profile presents a bar-like feature that is similar to those reported by Allison et al. (1995) and Jiang and Mehta (1996) from field measurements and laboratory experiments. The position of this bar-like feature clearly corresponds to an area of wave damping identified from high resolution satellite images. Details of the bottom sediment density are presented in Fig. 6d. The under-consolidated bottom layer extends $13-15 \mathrm{~km}$ offshore. Beyond, the mud density increases to a value of about 1450 $\mathrm{kg} \mathrm{m}^{-3}$, indicative of consolidated relict mud. 
The time series of fluid mud thickness along the Kourou harbour channel are shown in Fig. 7a. The results show the presence of a significant layer of fluid mud overlying the consolidated bed, and the thickness of which ranges from 0.6 to nearly $1.8 \mathrm{~m}$. Spatial variations in fluid mud thickness are mild compared to temporal variations which are quite marked. It is clear that dredging operations may lead to enhanced turbidity in the channel compared to the coast. However, the aim of the analysis is not to compare the occurrence of fluid mud in the channel and outside the channel, but only to consider the level of correlation between the thickness of the fluid mud layer in the channel and the intensity of wave forcing. The correlation reported in Fig. 7 between this thickness of the fluid mud layer and wave action clearly shows that waves play a major role in the oversiltation of the channel. This was further confirmed by the dredging authority. The data highlight a first phase of important mud accumulation towards the end of October 2002. It was followed by a second phase that attained a maximum towards mid-December. The wave height parameters, presented in Fig 7b, are strongly correlated with these muddy events: a first major wave forcing event $\left(T \approx 12 \mathrm{~s}, H_{s} \approx 2.1 \mathrm{~m}\right)$ occurred on the $23^{\text {rd }}$ October (day 296) and lasted three days. It was followed by a more intense event ( $\mathrm{T} \approx 12 \mathrm{~s}$, $H_{s} \approx 2.8 \mathrm{~m}$ ) a month later, on the $23^{\text {rd }}$ December 2002 (day 357). It is interesting to note that strong wave forcing persisted throughout January 2003. While the muddy accumulation associated with the preceding high energy phases persisted, the sustained high-energy levels in January did not generate further fluid mud supply.

The on-going experimental work on the intertidal muddy zone in Cayenne highlights, in even better detail, the temporal relationship between wave forcing and in situ liquefaction and onshore transport of fluid mud. The mud accumulation event that occurred on the $26^{\text {th }}$ September 2004 (day 269) was particularly rapid and intense. As shown in Fig. 8, a rapid increase in equivalent water depth pressure occurred on this day, 
caused by the massive and sudden arrival of nearly $90 \mathrm{~cm}$ of fluid mud. The ECMWF wave hindcast data for the September 26 event shows an important increase in $T$ and $H_{s}$ values $\left(T \approx 10 \mathrm{~s}, H_{s} \approx 1.7 \mathrm{~m}\right)$. The surface of this fluid mud remained relatively constant over the next 20 days, before decreasing gradually due to dispersive unloading and/or consolidation of the mud. Once again, this major accumulation event did not correspond to an extreme annual wave forcing event but happened after a prolonged calm period of more than three months.

\section{Discussion}

\section{Wave-mud interaction}

Comparison of the data on muddy bed profiles (Fig. 6), fluid mud layer thickness, and mud loading (Figs. 7a, 8a) with the pertinent wave data (Figs. 7b, 8b) highlights a close relationship between wave energy and fluid mud mobilisation in all three survey sites. Mud bank and inter-bank profiles show a wave-seabed interaction pattern that is in agreement with the conceptual muddy shore profiles proposed by Kirby (2000). Interbank areas are characterized by receding, low and concave erosion-dominated profiles of consolidated mud, while mud banks are characterized by prograding, high and convex accretion-dominated profiles of soft mud. As the tidal excursion proceeds in interbank areas, waves propagate further inshore, and at high tide, breaking occurs on the shore which is composed of either mangrove-colonised consolidated mud that may be eroded by the waves, or of sand beaches commonly subject to overwash, and associated with chenier formation. During the field survey in the Kaw area (Fig. 6), waves did not deviate significantly from the $2^{\text {nd }}$ order Stokes theory up to about $5 \mathrm{~m}$ water depth (11-13 km off- 
shore), but are totally dampened at water depths less than $1 \mathrm{~m}$ (6-8 $\mathrm{km}$ offshore). To reach this conclusion, we used the dispersion equation:

where $\omega=2 \pi / T$ is the wave radian frequency, and $k=2 \pi / L$ the wave number. The wavelength $L$ was deduced from remote sensing data and the water depth $h$ from the bathymetric survey. While propagating, the wave radian frequency was observed to remain nearly constant up to a depth of $5 \mathrm{~m}$.

The effect of waves over the mud bank profile is in good agreement with the physically suitable scenario proposed by Jiang and Mehta (1996) for wave-bank interaction. Because of thixotropic properties, the cyclic pressure gradients liquefy the 1-3 $m$ thick mud layer which is then transported en masse by shoreward wave drift due to wave asymmetry (Fig. 6b), and alongshore, due to the wave height gradient associated with oblique incidence. These wave liquefaction and mobilisation effects are highlighted by the time series of fluid mud thickness in the mouth of the Kourou navigation channel and by changes in bed level of the intertidal mudflat of Cayenne (Figs. 7 and 8). The data suggest that mud mobilisation by waves is clearly enhanced following long periods of low energy waves, and especially at the onset of the high wave energy season (October to May). Following such calm periods, even moderately energetic waves can lead to significant mud mobilization, exceeding that induced by succeeding higher energy waves. The first high energy events apparently generate high-density mud flows and mud spillover into the channel.

Although large waves account for high rates of mud liquefaction and mobilisation, such waves may not necessarily have a destructive impact on mangroves. An example is provided by the period 1995-2000 (Fig. 2b), during which wave energy increased 
considerably (Fig. 4). Mangroves in the inter-bank area underwent very active retreat (150 to $200 \mathrm{~m} \mathrm{y}^{-1}$ ), but at the same time the mud bank area experienced mangrove colonisation. This embodies, at first sight, an apparent contradiction, because intense wave forcing should lead to strong mud bank mobilisation. A possible explanation resides in the active formation and shoreward migration of mud bars towards the intertidal zone, as a result of the wave energy increase. This is clearly observed in Fig. 6b. With cessation of wave forcing, this mud forms a fluid gel-like body that accumulates in the form of mud bars. Such bars constitute the primary substrate for pioneer mangrove formation, as Lefebvre et al. (2004) have recently shown.

\section{Waves and mud bank migration}

The thrust thus far in the literature on mud bank migration has been on the role of drift generated by waves. The variability of mud bank migration rates highlighted by Gardel and Gratiot (2005) indeed shows strong time-dependence on the wave regime (Fig. 4). The high migration rate measured since 1995 coincides with higher wave energy. However, the quantitative relationship is rather poor. For the well documented 1979-1984 (Froidefond et al., 1988) and 1991-2002 periods (Gardel and Gratiot, 2005), there is indeed no linear relationship between mud bank migration rate and the wave forcing parameter. The mean mud bank migration rate of 1995-2000 is twice higher than that of 1979-1984, for instance, while the wave forcing parameter is only $4 / 3$ higher.

This poor quantitative relationship may be explained by several factors. A first source of divergence is oblique wave incidence, which provides a mechanism for longshore streaming of mud liquefied by strong wave action. The proportion of the longshore component of wave power, $P l$, relative to the shore-normal component $P n$, depends on wave breaking angle, and is given by the relationship (Komar, 1983): 


$$
P l=1 / 8 \rho g H_{s}^{2} \sin 2 \alpha
$$

As the angle increases from 0 to about $20^{\circ}$, so does $P l$. However, this component is always secondary to that of $P n$, and for the wave angles on the French Guiana coast (95 $\%<20^{\circ}$ ) ranges from zero to about $25 \%$ of the total wave power. Figure $4 \mathrm{~d}$ also shows a clear association of high wave energy phases with low incidence angles. The $10 \%$ and $30 \%$ highest waves are dominated by near-perpendicular, or slightly negative (southeastwards) wave approach angles, thus mitigating potential wave-induced longshore transport. Overall, therefore, high wave energy is a necessary condition for mud liquefaction and onshore transport, but the conditions for longshore streaming are not necessarily met. A second set of factors involves local irregularities such as nearshore bedrock outcrops and rocky headlands (Anthony and Dolique, 2004), river channel mouths and river discharge (Gardel and Gratiot, 2005), all of which are expected to significantly affect the migration or stabilization of mud banks. Closely related to this is the large-scale plan shape of the coast itself, which, in many areas, comprises alternations of mild capes and embayments that should affect wave drift gradients alongshore, especially during inter-bank phases. However, the overall dynamics underlying these alternations of capes and bays are not known (Lakhan and Pepper, 1997). A third source of divergence is the rheology of the mud banks. The rheological behaviour of the mud samples retrieved during the echo-sounding survey in Kaw shows a strongly non-linear and thixotropic response to stress (Aubry, 2003). Beyond a threshold forcing, the apparent mud viscosity $\mu_{\mathrm{m}}$ decreases considerably, and this would, in turn, induce an increase in mud bank migration rate, due to the increase of the $\rho_{w} H_{0}^{3} / \mu_{m} T^{2}$ parameter in 
equation (1). Finally, mud bank migration must also be conditioned by a combination of other higher-order forcing mechanisms, notably geostrophic forcing associated with the Guianas current, tidal currents propagating northwestwards, density currents due to the Amazon freshwater discharge, the effect of impinging wind stress on the shore, and the generation of compensatory northwestward flows due to north to northeasterly winds during the active trade wind season. A significant increase in wind velocities has occurred, for instance, since 1995, deduced from both the treated Atlantic wind pseudostress data and from data measured by the weather station in Kourou (Augustinus, 2004). While this increase seems to explain the corresponding increase in wave forcing, as suggested above from the pseudo-stress wind field in the Atlantic, it was also associated with high bank migration rates (up to $3 \mathrm{~km} \mathrm{y}^{-1}$ (Gardel and Gratiot, 2005)), while wave incidence angles for the highest waves were close to nil or even negative (Fig. 4d). Currents generated by wind stress would depend not only on wind velocities and incidence relative to the coast but also on shoreline morphology.

\section{Conclusions}

Past approaches attempting to explain the relationship between large-scale rates and patterns of mud bank migration on the muddy coast of South America between the Amazon and the Orinoco River mouths have been rather semi-empirical, based on inferences from long-term wind activity. They therefore do not provide a clear understanding of the physical relationship between forcing events, notably waves, and mud fluidization, transport, deposition and coastal erosion. Event-scale patterns of mud mobilisation on the mud-bank affected coast of French Guiana show a very good relationship with the ECMWF ERA-40 wave data generated by re-analysis of ocean 
surface wind waves, thus highlighting the usefulness of this database for coastal areas lacking wave records. The response of mud to wave forcing is adequately described using the wave parameters $H_{s}$ and $T$, the combination of these two parameters to yield an energy ratio $H_{0}{ }^{3} / T^{2}$, and the angle of wave incidence $\alpha$. Event-scale and short-term (order of days) mud liquefaction due to high wave energy events are particularly pronounced following long periods of low energy waves. On a longer-term basis, there has been a significant increase in the wave energy ratio responsible for higher rates of mud bank migration since the late 1980s, an increase apparently hinged on stronger wind stress over the Atlantic. However, the wave data also highlight a strong relationship between phases of high wave energy and low angles of wave incidence that tend to downplay the high migration rates expected from wave forcing. This suggests that mud bank migration is also controlled or modulated by other factors, including large-scale coastal features such as bedrock headlands and debouching river mouths, and ocean currents and tides. The ERA-40 wave dataset may be useful in future work aimed notably at fine-scale determination of the contribution of coastal features in alongshore mud bank migration, but there is a need for further work on the role of other hydrodynamic forcing mechanisms.

\section{Acknowledgements}

The work reported in this paper was carried out within the framework of the PNEC (Programme National Environnement Côtier) - French Guiana Experimental Site. A. Gardel was funded by a CNES (Centre National d'Etudes Spatiales) grant. Further funding was provided by the Research Council of the Université du Littoral Côte d'Opale. We thank the meteorological department of the Centre Spatial Guyanais and J. Servain 
and D. Corre (IRD, Plouzané, France) for providing wind data. Many thanks also to J. Bérault, J.P. Lefebvre, J.F. Ternon, J.P. Lamoureux and the cruise of the Direction Départementale de l'Equipement, French Guiana, for their invaluable help in collecting the ground data. The initial manuscript benefited from constructive reviews by J.T. Wells, P.G.E.F. Augustinus and two other reviewers. Denis Marin is thanked for preparing the figures.

\section{References}

Allison, M.A., Lee, M.T., 2004. Sediment exchange between Amazon mudbanks and shore-fringing mangroves in French Guiana. Mar. Geol., 208, 169-190.

Allison, M.A., Nittrouer, C.A., Faria, L.E.C., 1995. Rates and mechanisms of shoreface progradation and retreat downdrift of the Amazon river mouth. Mar. Geol. 125, 373-392.

Allison, M.A., Lee, M.T., Ogston, A.S., Aller, R.C., 2000. Origin of Amazon mudbanks along the northeastern coast of South America. Mar. Geol. 163, 241-256.

Anthony, E.J., Dolique, F., 2004. The influence of Amazon-derived mud banks on the morphology of headland-bound sandy beaches in Cayenne, French Guiana: a shortto long-term perspective. Mar. Geol., 208, 249-264.

Anthony, E.J., Gardel, A., Dolique, F., Guiral, D, 2002. Short-term changes in the plan shape of a sandy beach in response to sheltering by a nearshore mud bank, Cayenne, French Guiana. Earth Surf. Process Landf., 27, 857-866.

Aubry, T., 2003. Caractérisation et détermination du comportement rhéologique de vases du littoral guyanais. Rapport annuel du Chantier PNEC Guyane, 12-15. 
Augustinus, P.G.E.F., 1978. The changing shoreline of Surinam (South America). Ph.D. Thesis, Univ. Utrecht. 232 pp.

Augustinus, P.G.E.F., 2004. The influence of the trade winds on the coastal development of the Guianas at various scale levels: a synthesis. Mar. Geol., 208, 141-151.

Bouysse, P., Kudrass, H.R., Le Lann, F., 1977. Reconnaissance sédimentologique du plateau continental de la Guyane française (mission Guyamer 1975). Bulletin du Bureau de Recherches Géologiques et Minières 4, 141-179.

Caires, S., Sterl, A., 2005. A new nonparametric method to correct model data: application to significant wave height from the ERA-40 re-analysis. J. Atmospheric and Oceanic Technology, 22, 443-459.

Cleac'h, F., 1999. Les vasières du Quaternaire terminal sur les plateaux continentaux du Suriname et du Guyana (Amérique du Sud): modalités de formation et d'alimentation. Mémoire de D.E.A., Université de Bordeaux I.

Eisma, D., Augustinus, P.G.E.F., Alexander, C.R., 1991. Recent and subrecent changes in the dispersal of Amazon mud. Neth. J. Sea Res. 28, 181-192.

Froidefond, J.M., Pujos, M., Andre, X., 1988. Migration of mud-banks and changing coastline in French Guiana. Mar. Geol. 84, 19-30.

Fromard, F., Vega, C., Proisy, C., 2004. Half a century of dynamic coastal change affecting mangrove shorelines of French Guiana. A case study based on remote sensing data analyses and field surveys. Mar. Geol., 208, 265-280.

Gardel, A., Gratiot, N., 2005. A satellite image-based method for estimating rates of mud banks migration, French Guiana, South America. J. Coast. Res., 21, 720-728. 
Gratiot, N., Lefebvre, J.P., Baghdadi, N., Oliveros, C., 2003. Structuration des bancs de vase : rôle des barres vaseuses et hypothèses de fonctionnement. 9ème Congrès des Sédimentologues Français, ASF, Bordeaux, 14-16 October, 2003.

Jiang, F., Mehta, A.J., 1996. Mud banks of the southwest coast of India. V: Wave attenuation. J. Coast. Res., 12, 890-897.

Kirby, R., 2000. Practical implications of tidal flat shape. Cont. Shelf Res., 20, 10611077.

Komar, P.D., 1983. Nearshore currents and sand transport on beaches. In: Johns, B. (Ed.), Physical Oceanography of Coastal and Shelf seas. Elsevier, Amsterdam, 67-109.

Komen, G.L., Cavaleri, L., Donelan, M., Hasselmann, K., Hasselmann, S., Janssen, P.A.E.M. 1994. Dynamics and Modeling of Ocean Waves. Cambridge University Press, Cambridge.

Lakhan, V.C. and Pepper D.A., 1997. Relationship between concavity and convexity of a coast and erosion and accretion patterns. J. Coast. Res., 13, 226-232.

Lefebvre, J.P., Dolique, F., Gratiot, N. 2004. Geomorphic evolution of a coastal mudflat under oceanic influences: an example from the dynamic shoreline of French Guiana. Mar. Geol., 208, 191-205.

Mathew, J., Baba, M., 1995. Mudbanks of southwest coast of India: Part II - Wave-mud interaction. J. Coast. Res., 11, 179-187.

NEDECO, 1968. Surinam transportation study: report on hydraulic investigation. The Hague, Netherlands, 293 pp.

Plaziat, J.C., Augustinus, P.G.E.F., 2004. Evolution of progradation/erosion along the French Guiana mangrove coast: a comparison of mapped shorelines since the 18th century with Holocene data. Mar. Geol., 208, 127-143. 
Pujos, M., Bouysse, P., Pons, J.C., 1990. Sources and distribution of heavy minerals in Late Quaternary sediments of the French Guiana continental shelf. Cont. Shelf Res., $10,59-79$.

Rodriguez, H.N., Mehta, A.J., 1998. Considerations on wave-induced fluid mud streaming at open coasts. In: Black, K.S., Paterson, D.M., Cramp, A. (Eds.), Sedimentary Processes in the Intertidal Zone. Spec. Publ. Geol. Soc. London, 139, 177-186.

Sterl, A., Caires, S., 2005. Climatology, variability and extrema of ocean waves - the web-based KNMI/ERA-40 Wave Atlas. Int. J. Climatology, 25, 963-977.

Wells, J.T., 1983. Dynamics of coastal fluid muds in low-, moderate-, and high-tide-range environments. Can. J. Fish. Aquat. Sci, 40, 130-142.

Wells, J.T., Coleman, J.M., 1978. Longshore transport of mud by waves: northeastern coast of South America. Geol. en Mijnb. 57, 353-359.

Woods, A., 2005. Medium-Range Weather Prediction: The European Approach. Springer, Berlin.

\section{Figure captions}

Fig. 1. Regional setting of the French Guiana coast, showing the field experimental sites of Kourou, Anse de Chaton (Cayenne) and Kaw. Black lines with white circles near Kaw show profile surveys and bed sediment sample locations. Broken black lines show longshore stretches of coast affected by mud banks, which alternate with inter-bank areas of coast. Cross shows ERA- 40 wave dataset point at $5^{\circ} \mathrm{N}, 52^{\circ} \mathrm{W}$. Inset shows the Kourou navigation channel with distances to ESA harbour. 
Fig. 2. (a) Longshore mud bank migration rates between Cayenne and Kourou (see Fig. 1), from 1979 to 1984 (based on aerial photographic interpretations by Froidefond et al., 1988), and from 1992 to 2002 (based on satellite image interpretation by Gardel and Gratiot, 2005); (b) bank and inter-bank mangrove shoreline evolution trends between Cayenne and Kourou from 1988 to 2002 (from Gardel and Gratiot, 2005).

Fig. 3. The daily averages of wave climate parameters, $H_{s}$ and $T$, derived from ERA-40 data averaged over the period $1960-2004$ at $5^{\circ} \mathrm{N}, 52^{\circ} \mathrm{W}$. Dots correspond to the first and third inter-quartiles, and circles to the median values.

Fig. 4. Inter-annual fluctuations of the wave parameters $H_{s}, T, H^{3} / T^{2}$ and $\alpha$ over the period 1960-2004. Grey bar indicates years with faulty wave height data (Sterl and Caires, 2005).

Fig. 5. Inter-annual wind speed fluctuations over the central Atlantic pseudo-fetch area over the period 1965-2002 (see appendix for derivation of data).

Fig. 6. (a), (b) Inter-bank and mud bank profiles and schematic wave attenuation patterns. MWL is the Mean Water Level and MTR the Mean Tidal Range deduced from tidal signal series provided by the French Service Hydrographique et Océanographique de la Marine; (c), (d) associated sed iment surface concentration profiles; the circle diameter is representative of the vertical error bar. 
Fig. 7. (a) Spatio-temporal distribution of the fluid mud layer in the Kourou navigation channel; (b) wave parameter fluctuations and their comparison with the thickness of the fluid mud layer along the channel (calculated as the mean of the three highest values measured along the channel axis for the period October 2002 to January 2003); arrows show peaks in fluid mud layer thickness corresponding to major peaks in $H_{s}$ and $T$.

Fig. 8. (a) Time series of maximum high water levels (Max WL) essentially due to tidal oscillations, and of the equivalent water pressure, $p_{w}$, measured by the pressure sensor deployed on the intertidal mudflat; (b) corresponding time series of the main wave parameters. 


\section{Appendix}

The IRD tropical Atlantic pseudo-stress data used are matric es of 25 lines and 38 rows. 473 monthlyaveraged matrices covering the $\left(30^{\circ} \mathrm{N}-30^{\circ} \mathrm{S}, 120^{\circ} \mathrm{E}-70^{\circ} \mathrm{W}\right)$ geographic position were used to obtain the mean Eulerian directions and intensities of trade winds and the ir corresponding standard deviations. Results of the calculation are reported in Fig. A. The trade winds affecting the French Guiana coast are characterized by a quasi-constant direction throughout the year. When examining the mean and standard deviation of the monthly-averaged pseudo-stress wind directions from 1964 to 2003 , the trade wind regions are clearly delimited (Fig. A.i,ii). They correspond to the dark areas, associated with a small standard deviation $\left(0-10^{\circ}\right)$. In these areas, winds blow almost permanently in the same direction but also with a rather strong intensity as can be seen in Fig. A.iii. Thus, the monthly-averaged pseudo-stress wind values attain maximum intensities of about $60 \mathrm{~m}^{2} \mathrm{~s}^{-2}$ in the $10-20^{\circ} \mathrm{N}$ trade wind region. As illustrated in Fig. A.iv, wind velocity fluctuations can be important, es pecially offshore of French Guiana (indicated by a 'star') where the standard deviation can reach $25 \mathrm{~m}^{2} \mathrm{~s}^{-2}$. Actually, this corresponds to monthly fluctuations, so that the standard deviation is considerably reduced when considering inter-annual variability.

To determine the climatology of the oceanic wind field that interacts with the French Guiana coast, a necessary first step consists in delimiting the associated fetch area. This fetch area cannot be strictly delimited from the availab le monthly-averaged wind field data. It is therefore more appropriate to consider a monthly averaged pseudo-fetch area. From the 456 monthly-averaged wind pseudo-stress direction matrices available, it is possible to establish a month-to-month pseudo-fetch area, but for simplicity it has been decided to consider a time-independent area. This latter is represented by small circles in Fig. A.i. This choice of a geographic ally constant pseudo-fetch area is physically suitable because it fits with the location of the trade wind region so that wind direction can be considered as almost constant. This choice simplifies the month-to-month matrix comparisons because the area considered is constant. The pseudo-fetch area thus determined covers $\mathrm{N}=48$ points of each matrix with line and row coordinates regrouped in the 48 elements vectors if and jf.

The mean wind velocity Uf in the pseudo-fetch area is then calculated from the month-to-month pseudostress wind velocity matric es using the following equations: 


$$
U_{x}([i f, j f])=\frac{\tau_{x}([i f, j f])}{\left(\left(\tau_{x}([i f, j f])\right)^{2}+\left(\tau_{y}([i f, j f])\right)^{2}\right)^{1 / 4}}
$$

A.a)

$$
U_{y}\left([i f, j f]=\frac{\tau_{y}([i f, j f])}{\left(\left(\tau_{x}([i f, j f])\right)^{2}+\left(\tau_{y}([i f, j f])\right)^{2}\right)^{1 / 4}}\right.
$$

A.b)

$$
U_{f}=\frac{1}{N} \sum_{i=1}^{N} \sqrt{U_{x}(i f(i), j f(i))^{2}+U_{y}(i f(i), j f(i))^{2}}
$$

A.c)

where $\tau_{x}$ and $\tau_{y}$ are the two horizontal components of the pseudo-stress wind field matrices, and $U_{x}$ and $U_{y}$ the two horizontal components of the wind field velocity in the pseudo-fetch area.

Equations $\mathrm{Aa}, \mathrm{Ab}$ and $\mathrm{Ac}$ do not provide an accurate estimate of the wind velocity, because the root square of the monthly averaged pseudo-stress data deviates mathematically from the monthly averaged root square pseudo-stress. For this reason, the time evolution shown in Fig. 5 of the mean wind velocity Uf in the pseudo-fetch area is discussed in a rather qualitative than quantitative way. 

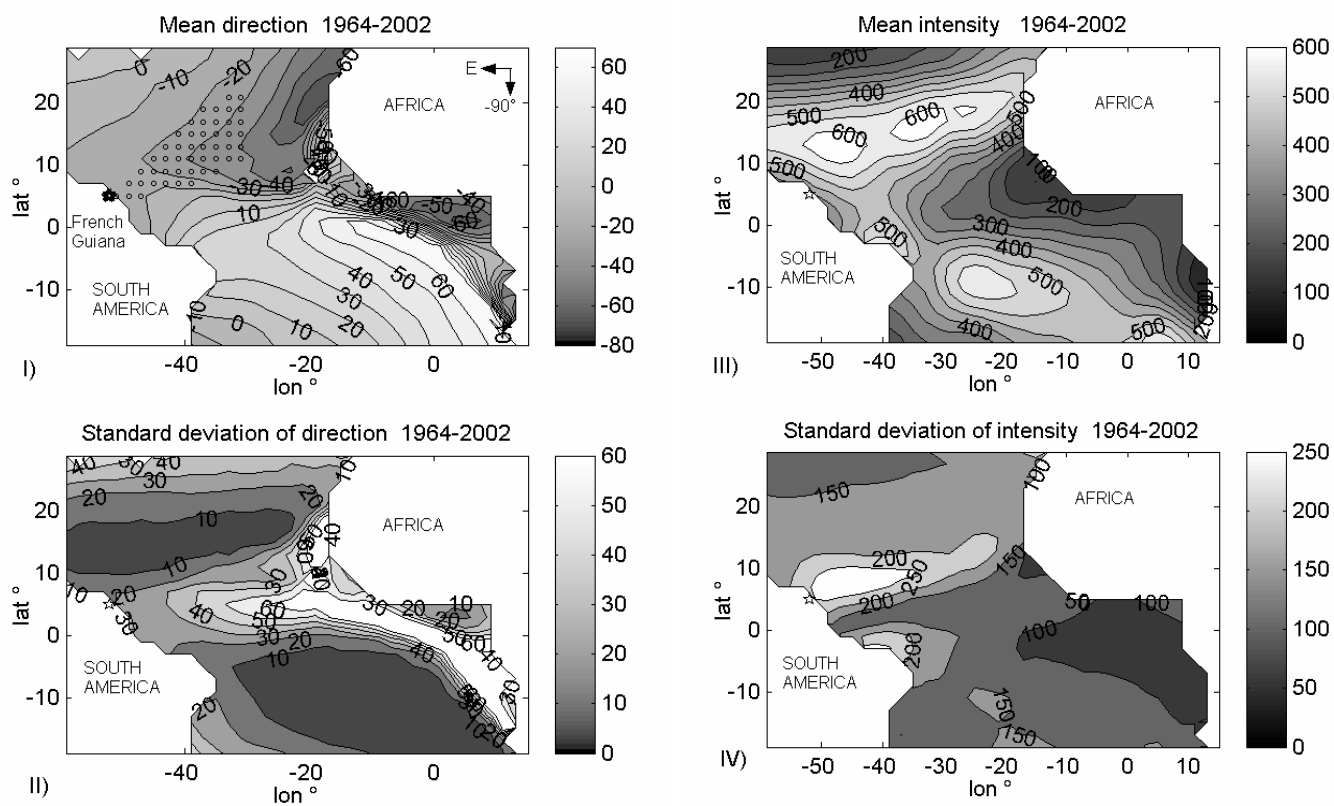

Fig. A.i. Monthly-averaged wind pseudo-stress direction from 1964 to 2002. The dotted area repres ents the fetch region considered for the generation of waves that concern French Guiana; A.ii. standard deviation corresponding to temporally averaged data reported in Fig. A.i; A.iii. Mean annual wind pseudo stress intensity (in $1 / 10$ of $\mathrm{m}^{2} \mathrm{~s}^{-2}$ ) from 1964 to 2002; A.iv. standard deviation corresponding to temporally averaged data reported in Fig. A.iii. 


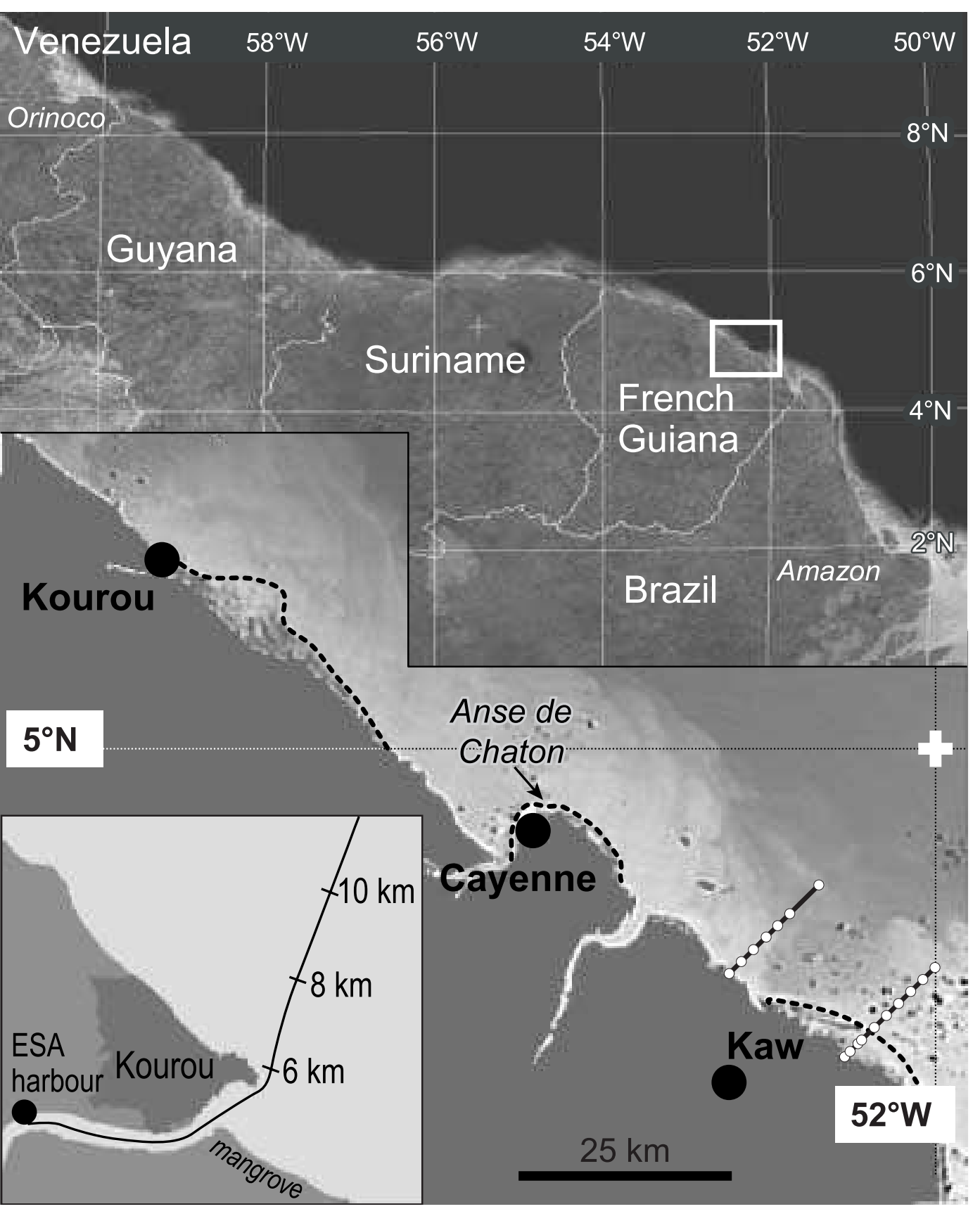


Figure 3

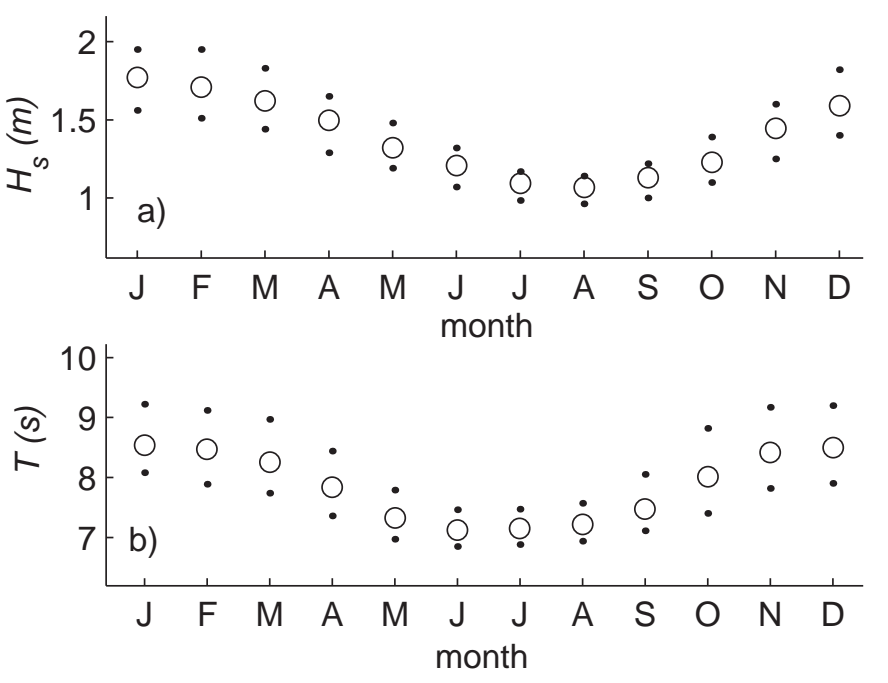


Figure 5

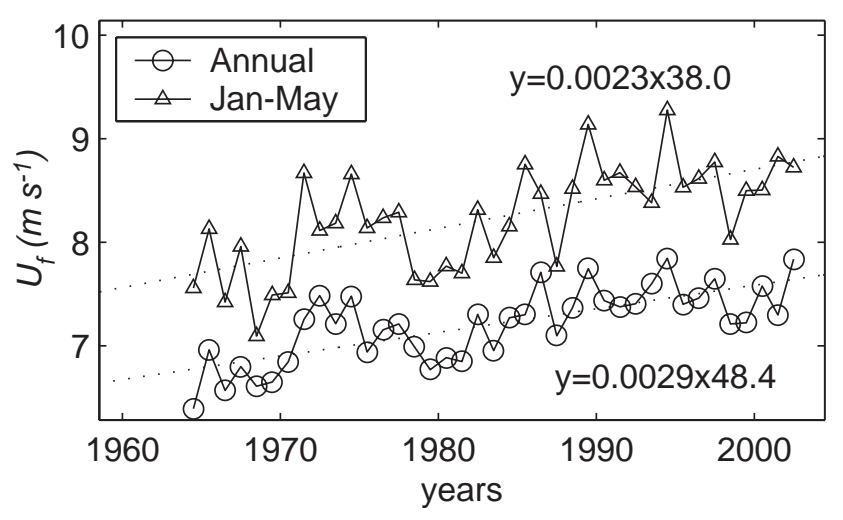


a)
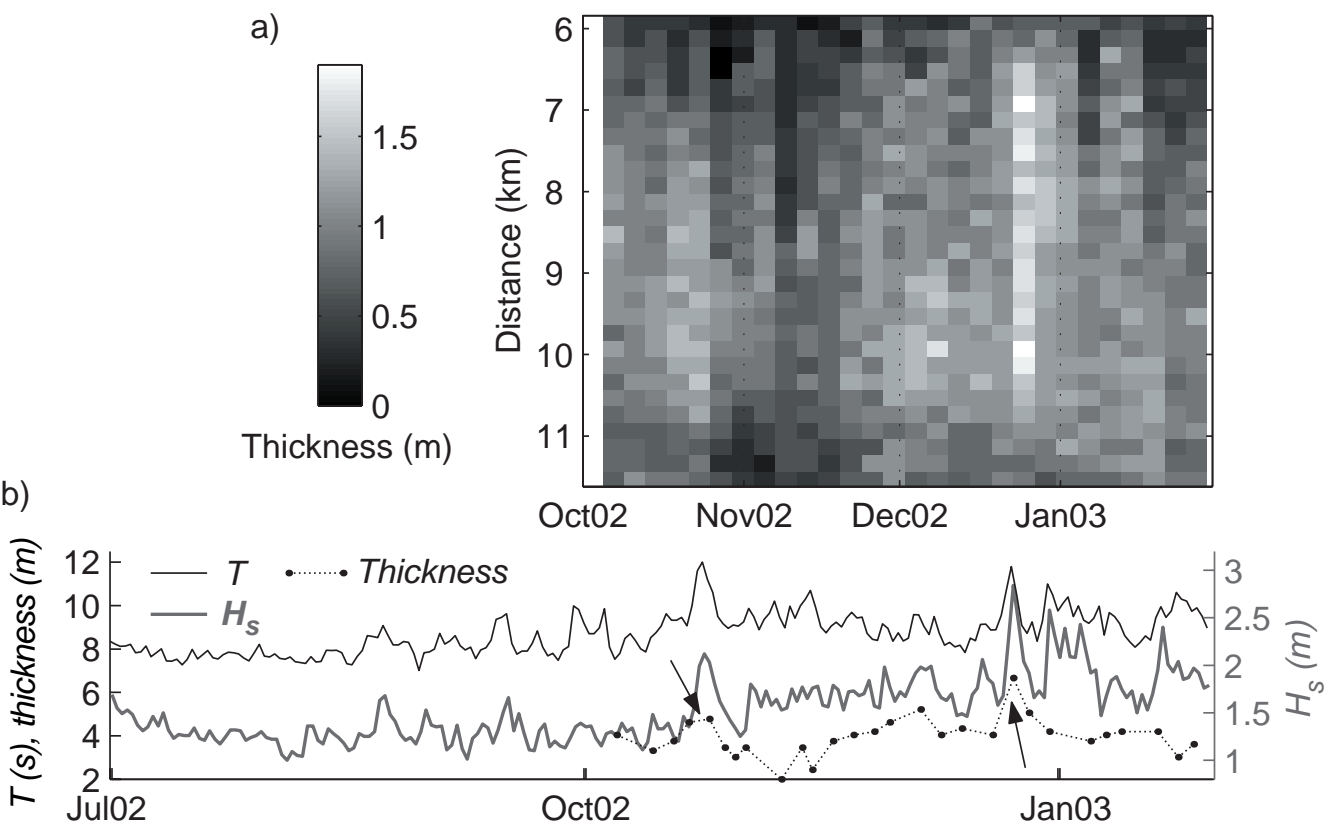
